\title{
Opioid Prescribing Risk Management Opportunities for the Advance Nurse Practitioners
}

Robert Smith

Department of Podiatry, works in ORMOND BEACH, FL, Ormond Beach, Florida, USA

Corresponding Author: Robert Smith, Department of Podiatry, works in ORMOND BEACH, FL and specializes in Podiatry, Ormond Beach, Florida, USA

Received date: August 02, 2021; Accepted date: Augusł 22, 2021; Published date: September 01, 2021

Citation: Robert Smith (2021). Opioid Prescribing Risk Management Opportunities for the Advance Nurse Practitioners. J. Clinical Research Notes. 2(1). DOI: 10.31579/2690-8816/035

Copyright: (C) 2021 Robert Smith, This is an open-access article distributed under the terms of the Creative Commons Attribution License, which permits unrestricted use, distribution, and reproduction in any medium, provided the original author and source are credited.

\begin{abstract}
All clinicians are ethically obliged to prescribe responsibly and cautiously to diminish the potential for opioid diversion and to help minimize the growth of the current opioid abuse epidemic. Advance nurse practitioners should establish procedures to better control and limit opioid prescription and develop analgesic regimens to treat pain. The main purpose and goal for this review is to present data congruent with clinical, medical, and legal reports for allowing an appreciation of the possibility of the risk assumed when ordering and prescribing opioids within our podiatry profession. First, the concept and process of risk management as illustrated using a root cause analysis approach will be introduced as well as applying these principles specifically to opioid prescribing will be presented. Then, several examples found in both medical and legal literature documenting the reasons for opioid prescription risk will be presented. Finally, mitigating strategies for safe opioid prescribing will be presented so that mitigation of opioid harm can be possible and realized by the advance nurse practitioner.
\end{abstract}

Key words: opioids; risk; management; pain; doctors; opioid; economic; drugs; medication

\section{Introduction}

The seasoned astute advance nurse practitioner will remember the national push in 1996 for identification of pain as a primary medical disorder and the approval of oxycodone hydrochloride, popularly known by its brand name OxyContin ${ }^{\circledR}$, as a 'minimally addictive pain reliever' by the Food and Drug Administration (FDA) in the same year $[3,13,17,22,23]$. On July 17,2020 , relying on public data including up-todate government studies and new reports in medical literature, Mann revealed that prescriptions for half of all Americans for at least one opioid were being written each year. Patients are still receiving more than twice the volume of opioids considered normal before the prescribing boom in the late 1990s $[13,20,22,23]$.The opioid epidemic is considered to have occurred in three waves [3]. The first wave began in 1991 when deaths involving opioids began to rise sharply, with a spurt in the prescription of opioids or opioid-combination medications for treating pain [3]. This increase was influenced by reassurances from pharmaceutical companies and medical societies or associations, emphasizing the low risk of addiction from such medications. Bachtell (2019) has reported that dozens of opioid manufacturers, distributors, pharmacies, and doctors turned a blind eye to the opioid crisis swamping the United States.

Van Zee (2009) used the "Oxycontin ${ }^{\circledR}$ Marketing Plans from 1996-2001" to validly argue that the manufacturers of OxyContin ${ }^{\circledR}$ pursued an "aggressive" marketing campaign to promote the use of opioids by emphasizing the greater benefits of opioid-based products over others without disclosing the involved risks. Ellenbogen and Segal (2020) published their findings in a report examining the differences in opioid prescriptions among general physicians, nurses, and physician assistants. They conducted a serial cross-sectional analysis of the data regarding the prescription claims during 2013-2016, collected from the public domain of the Centers for Medicare and Medicaid Services (CDC) [7]. The analysis demonstrated relatively higher rates of opioid prescriptions among nurses and physician assistants [7]. The factor contributing to this high rate among midlevel healthcare professional may be understood by a piece of recent news, which reports that Purdue Pharma told pharmaceutical representatives "that midlevel providers are critical to our success" and referred to them as "high-value Oxycontin ${ }^{\circledR}$ prescribers" in a 2015-2016 training session [16]. From all these, a valid argument can be made that opioid oligopoly got so enmeshed in greater profiteering that it forgot to abide by the most important aspect of healthcare - the ethical responsibility to do no harm and to stand as a community leader.

The act of prescribing involves many subtle influences and ethical issues, yet the consequences are almost wholly borne by the patient. All clinicians are ethically obliged to prescribe responsibly and cautiously to diminish the potential for opioid diversion and to help minimize the growth of the current opioid abuse epidemic. Advance 
nurse practitioners' practices should establish procedures to better control and limit opioid prescription and develop analgesic regimens to treat pain. Opioid analgesics should be prescribed by balancing their beneficial and adverse effects [21]. While the ramifications of prescribing opioids are both social and economic, the specific act itself involves two parties - the practitioner and the patient. The role of the advance nurse practitioner is to responsibly provide pain management in an error-free environment while adhering to both state and federal regulations such as the Centers for Disease Control's guidelines to assist physicians in effectively managing pain amid the opioid crisis [5]. The main purpose and goal for this review is to present data congruent with clinical, medical, and legal reports for allowing an appreciation of the possibility of the risk assumed when ordering and prescribing opioids within our podiatry profession. First, the concept and process of risk management will be introduced, and the application of these principles specifically to opioid prescribing will be presented. Then, to enrich the provider's body of knowledge, several examples found in both medical and legal literature documenting the reasons for opioid prescription risk will be presented. Finally, mitigating strategies for safe opioid prescribing will be presented so that mitigation of opioid harm can be possible and realized by the advance nurse practitioner.

\section{Risk Management Principles}

Risk identification mainly involves brainstorming as in the process of root cause analysis. A business, e.g., a medical practice, gathers its employees together so that they can review all the various sources of risk. The next step is to arrange all the identified risks in order of priority. Because it is impossible to mitigate all existing risks, prioritization ensures that those risks that can affect a business practice of prescribing opioid significantly are dealt with more urgently.

The next step is assessing the risks; in many cases, problem resolution involves identifying the problem and then finding an appropriate solution. However, prior to figuring out how best to handle risks, the clinical provider should locate the cause of the risks by asking the simple question, "What caused such a risk and how could it influence the art of pain management as in prescribing opioid products?" Once the medical provider entity is set on assessing likely remedies to mitigate identified risks and prevent their recurrence, they need to ask the following questions: "What measures can be taken to prevent the identified risk from recurring? Furthermore, what is the best thing to do if it does recur?"

Finally, the advance nurse practitioner must develop preventive mechanisms for identified risks within the context of prescribing opioids. The proactive narrative can be as simple as the following: "Here are the ideas that were found to be useful in mitigating risks and are now developed into a number of tasks and then into contingency plans deployable in the future. If risks occur, the plans can be activated.

Risk management is an important process when prescribing any medication, especially "opioids," because it empowers a prescriber with the necessary tools to adequately identify and deal with potential risks of opioids. Once a risk has been identified, mitigating it easy. Additionally, risk management provides the opioid prescriber with a basis for undertaking sound decision-making. For the pain prescriber, assessment and management of risks is the best way to prepare for potential eventualities in the path of progress and growth. When prescribers evaluate their plan for handling potential threats and develop structures to address them, the process improves their odds for successful opioid prescribing. Additionally, progressive opioid prescribing risk management ensures that high priority risks are dealt with as aggressively as possible. Moreover, the management process will have the necessary information that they can use to make informed decisions and ensure that the profession remains viable.

\section{Opioids and Medical Malpractice}

Lowes (2017) reports that a medical liability insurer found that prescription painkillers are the basis of more medical malpractice claims involving drug errors than from any other drug class. The company analyzed more than 10,000 closed malpractice claims from 2012 through 2016. Twenty-four percent of medication-related claims involved opioids even though these drugs accounted for only about $5 \%$ of the prescription drugs dispensed in 2016, according to published data from Quintiles IMS [12]. Claims often involve overdose, as well as allegations that patients developed addiction to painkillers. Over a third of opioid-related malpractice claims involve errors or failures during the follow-up phase of prescribing. Physicians commonly renewed prescriptions without appropriately monitoring them. Further, an effective legal service internet advertisement summarizes that both Centers for Disease Control and Prevention (CDC) and the U.S. FDA have reviewed medical malpractice claims for opioid prescriptions and assert that none of the prescribing physicians had followed the necessary steps recommended by both agencies' intended published guidelines [14]. There was little attention to assessing and educating patients before prescribing opioids. Doctors who bypass these crucial steps increase the likelihood of a patient developing an opioid addiction [14].

Hazi (2019) offers and defines three of the most common claims in opioid medical malpractice litigation:

(1) Lack of medical necessity: plaintiffs' attorneys allege that their clients were prescribed medically unnecessary opioids, either because no treatment was indicated or because an alternative (nonopioid) treatment option was available [8].

(2) Over prescription of opioids: Claims alleging overprescription of opioid medications are common as well. This includes claims of unnecessarily relying on opioid medications for treatment of pain and other conditions, overdosing individuals under inpatient and outpatient care, and failing to reduce a prescription when indicated[8].

(3) Failure to monitor: Once patients have been prescribed opioid medications, failure to monitor them adequately for signs of dependency (investigating refilling prescriptions without assessing adequately) can also be the basis for a medical malpractice claim [8] - As the nation's opioid epidemic continues, physicians are increasingly facing scrutiny regarding their prescription practices. In fact, opioid-related medical malpractice claims have become so prevalent that some insurers are now writing policies specifically covering opioid lawsuits [8].

Berman and Li (2020) report that the US news media has reported on an increasing number of opioid-related criminal cases against physicians from a wide variety of clinical specialties. The most commonly convicted crime in these cases is drug trafficking, followed by fraud, money laundering, and manslaughter [2]. They report that the annual number of criminal cases against physicians charged with opioid-related offenses reported in the US news media increased from 0 in 1995 to 42 in 2019 [2]. Moreover, of the 372 physician defendants in these criminal cases, $90.1 \%$ were male, $27.4 \%$ were 65 years and older, and $23.4 \%$ were charged in Florida [2]. Finally, drug trafficking was the most convicted crime (accounting for $54.2 \%$ of all convicted cases), followed by fraud $(19.1 \%)$, money laundering (11.0\%), and manslaughter (5.6\%) [2].

Kim and Sibai (2020) have reported that the overall risk of DEA action as a percentage of total physicians is small but not insignificant; however, the overall rates of DEA prosecution have increased. Also, new risk factors include the type of degree of the physician (osteopath versus allopath) and being in private practice, with a subtle trend toward foreign graduates being at higher risk [11] .Finally, they proclaim that more subtle charges have been added involving interpretation of the medical 
purpose of opioids and standard of care for their use [11]. It is an understandable inference that as the need for midlevel providers intensifies and their resulting responsibilities increases that opioid prescribing litigation and malpractice claims will a for gone conclusion.

\section{Mitigating Opioid Prescribing Risk}

Thorough and diligent documentation and opioid monitoring by the opioid prescriber are the most effective foundations for building a defense in an opioid medical malpractice case. Over prescribing opioids can cause the death of the patient, especially though overdose. The appropriate kind of civil action to file is a wrongful death lawsuit, not a personal injury lawsuit. One tool that will assist the podiatric physician with both documentation and monitoring is the Opioid Stewardship Program, which may be described as coordinated interventions designed to improve, monitor, and evaluate the use of opioids to support and protect patients [24, 26]. The advance nurse practitioner can appreciate the concept of opioid stewardship has its origins and principles in current established antimicrobial stewardship accepted in all practices. There are seven fundamental actions to support the practice of opioid stewardship within the inter-professional health care arena: (1) Promotion by leadership to commit to change in current culture, (2) Implementing organizational polices, (3) Advancement of clinical knowledge, expertise, and practice, (4) Enhancement of patient and family caregiver education and engagement, (5) Tracking, monitoring, and reporting performance data, (6) Establishment of accountability, (7) Supporting a network with community collaboration[15,18,28,29].

Yorkgitis and Brat (2018) reported that many opioid prescription medications after surgery go unused, with the potential for diversion and misuse. Further, they assert as surgeons become increasingly aware of their role in opioid misuse, better tools are needed to guide behavior. Based on an extensive review of recent literature, they developed the acronym RIGHTT: Risk for adverse event, Insight (it is important) that surgeons recognize the potential for opioid misuse in their patients, Going over pain plan, Halting opioids, Tossing unused opioids and Trouble identification [29] . RIGHTT provides a simple acronym for surgeons to integrate best-practice strategies into their management of post-surgical opioids [29].

Varley and Zuckerbraun (2018) proposed their proactive reform in a way surgeons may approach pain management to observe opioid stewardship. They proposed the acronym REDUCE: Recognize risk, Educate patients, Discuss patient expectations and the proposed plan, Use multimodal therapy, Controlled prescribing, and Early referral to pain specialists. ${ }^{22}$ REDUCE provides another simple acronym for surgeons to integrate best-practice strategies into their management of post-surgical opioids [28]. Recently the detail proposed acronym "MORPHINE" to help shape prescription opioid strategies use for lower extremity pain. Clinical-based evidence will be presented to defend the use of the "MORPHINE" acronym by providing an argument high lighting current ethical prescribing standards, legal regulations, and opioid stewardship aimed at alleviating the widespread opioid crisis that prescribing providers face daily $[23,24,18]$.

"M" is for Multimodal analgesic strategies [24, 26]. Multimodal analgesia techniques for lower extremity surgery are now widely practiced reducing opioids and opioid related adverse effects. A multimodal approach is likely to produce superior analgesia than an opioid based approach because multimodal analgesic agents target a variety of pain pathways [24,25].

A multimodal analgesic approach is likely to produce superior analgesia over an opioid-based approach because multimodal analgesics target a variety of pain pathways. An essential duty of the advance nurse practitioners who prescribes opioid is to recognize and reduce risks for opioid harm $[24,26]$.Therapeutic success depends on proper candidate selection, assessment before administration of opioid therapy, and close patient monitoring [24,25]. Pain management specialists can enhance a patient's ability to function and improve their quality of life [24,25].

"O" is for Opioid Formulary [24, 25]. One of the mission pillars of an opioid stewardship program is to limit opioid initiation by creating prescribing opioid guidelines $[24,25,18]$. The advance nurse practitioner can create their own personal opioid formulary by rigorously and using one or two drugs for each clinical condition they commonly encounter.

"R" is for Recognize and Reduce the Risk for opioid harm to the patient $[24,25]$. This letter of the acronym is borrowed and hybridizes both Yorkgitis and Brat's and Varley and Zuckerbraun's acronyms [29, 28]. Therapeutic success depends on proper candidate selection, assessment before administering opioid therapy, and close monitoring throughout the course of treatment [24, 25].

"P" is for Pharmacokinetics and Pharmacodynamics of opioids [24,26] . Advance nurse practitioners must beware of dangerous combinations resulting in deadly drug interactions. Sometimes dangerous drug combinations are indeed prescribed for legitimate reasons, without recognition of the possible dangerous effects. Further, diseases of a patient's organ system may affect or be affected by opioid treatments [24, 25]. "H" is for Help seek a pain specialist when warranted [24, 25]. Pain management specialists can empower a patient's ability to function and their quality of life while living with pain. Patients with substance use disorders with medically legitimate pain sufficient to justify opioids must be closely monitored [24,25,18].

"I" is for use Information technology. The ability to use information technology resources is critical to provide benchmarking of opioid use and the collection of metrics to create clinical decision support tools to build best practice models [24,26,18] .

"N" is for the Number of opioid doses [24-26]. Opioid stewardship programs' paramount mission is to limit opioid commencement $[24,26,18]$. Ideally, opioid analgesics are prescribed by balancing the beneficial and adverse effects. The appropriate combination of agents, including opioids and adjunctive medications, may be seen as "rational pharmacotherapy" and provide a stable therapeutic platform from which to base treatment changes [24,26].

"E" is for education and outreach to multidisciplinary stakeholders, representatives of healthcare disciplines to include the advance nurse practitioners as well as both patients and patient care givers $[25,18]$. It is paramount how important it is for patients to understand that the goal of postoperative pain management as asserted by Varley and Zuckerbraun (2018) is not to be pain free but to make the pain manageable in the context of a patient's daily activities during their recovery.

Pollock et al. (2007) offers and describes a systematic strategy for appropriate prescribing of opioid analgesics to minimize poor-quality and erroneous prescribing and can thus be another self-directed tool for risk mitigation. This eight-step approach to prescribing suggests that the physician should (1) evaluate and dearly define the patient's problem; (2) specify the therapeutic objective; (3) select the appropriate drug therapy; (4) initiate therapy with appropriate details and consider nonpharmacologic therapies; (5) give information, instructions, and warnings; (6) evaluate therapy regularly (e.g., monitor treatment results, consider discontinuation of the drug), (7) consider drug cost when prescribing; and (8) use computers and other tools to reduce prescribing errors [19]. These eight steps, along with ongoing self-directed learning, comprise a systematic approach to efficient and practical prescribing for 
the podiatric physician [19]. The CDC recommends the following strategies for opioid prescribers: Assess, Check, Discuss and Observe to detect signs of harm related to long-term opioid therapy [4]. Thus this $\mathrm{CDC}$ recommendation can assist the podiatric physician with mitigating opioid harm as a risk reduction strategy.

(1) Assess: Evaluate for risk factors, such as a history of substance use disorder or respiratory conditions that could increase the patient's risk for harm from opioid therapy [4].

(2) Check: Use drug testing and check the prescription drug monitoring program to ensure the patient is not taking too high an opioid dosage or combining opioids with other drugs, which could raise their risk for drug interactions [4],

(3) Discuss: Ask the patient about their concerns to determine whether they are experiencing any ill effects, such as nausea or over sedation [4].

(4) Observe: Look for slurred speech or abnormal gait [4].

Mitigating strategies to prevent opioid overdoses and deaths are presented in Table 1.

\section{Strategies to Mitigate and Reduce Opioid Deaths}

- Assure medical necessity of opioids

- Use opioid agreements

- Screen and risk stratify patients

- Use prescription drug monitoring programs

- Titrate slowly

- Reduce dose when switching between opioids

- Be cautious when rotating to methadone

- Require secure storage

- Remember that all opioid prescriptions are a trial, and discontinue if benefit does not warrant the risk

- Providing opioid medications to patients who die from their effects can expose physicians and pharmacists

Table 1. Strategies to Mitigate and reduce Opioid deaths

The effectiveness of this clinical coping effort depends on the type of opioid issue and/or conflict, the individual, and their circumstances. Clinical coping suggestions regarding to dosing opioids within the context of demographics and disease states are summarized and presented in Table 2. 


\begin{tabular}{|c|c|c|}
\hline \multicolumn{3}{|c|}{ Clinical Coping with Prescribing Opioid Analgesics and Disease States } \\
\hline Prescribed Opioids & $\begin{array}{l}\text { Presenting Demographics and Disease } \\
\text { State }\end{array}$ & $\begin{array}{l}\text { Recommendations for Opioid } \\
\text { Prescribing }\end{array}$ \\
\hline Opioid Analgesic Class & Elderly- Greater than 70 years old & $\begin{array}{l}\text { Approximately } 25 \% \text { to } 50 \% \text { of the } \\
\text { adult recommended starting dose, } \\
\text { and then slowly titrated to pain relief }\end{array}$ \\
\hline Opioid Analgesic Class & Obesity & $\begin{array}{l}\text { Lean body weight is the optimal } \\
\text { dosing for opioids agents. }\end{array}$ \\
\hline Opioid Analgesic Class & Female Sex & $\begin{array}{l}\text { Use a minimal dose for a short } \\
\text { period of time }\end{array}$ \\
\hline \multirow[t]{2}{*}{ Codeine } & $\begin{array}{l}\text { Not recommended in patients with renal } \\
\text { insufficiency }\end{array}$ & $\begin{array}{l}\text { Accumulation of active metabolites } \\
\text { in renal failure }\end{array}$ \\
\hline & $\begin{array}{l}\text { Not recommended in patients with liver } \\
\text { insufficiency }\end{array}$ & $\begin{array}{l}\text { Impaired conversion of codeine to } \\
\text { morphine (active metabolite) }\end{array}$ \\
\hline \multirow[t]{2}{*}{ Fentanyl } & $\begin{array}{l}\text { Parent compound may accumulate with } \\
\text { renal insufficiency }\end{array}$ & \multirow[t]{2}{*}{$\begin{array}{l}\text { No increase in adverse effects have } \\
\text { been reported }\end{array}$} \\
\hline & $\begin{array}{l}\text { Pharmacokinetics were not altered in } \\
\text { patients with cirrhosis }\end{array}$ & \\
\hline \multirow[t]{2}{*}{ Hydromorphone } & $\begin{array}{l}\text { Hydromorphone-3-glucuronide can } \\
\text { accumulate and cause CNS toxicity }\end{array}$ & $\begin{array}{l}\text { Avoid use in Patients on dialysis and } \\
\text { patients with GFR less than } 30 \\
\mathrm{ml} / \mathrm{min}\end{array}$ \\
\hline & $\begin{array}{l}\text { Risk accumulation of parent drug due to } \\
\text { decrease conversion }\end{array}$ & $\begin{array}{l}\text { Recommend to decrease dose by } \\
50 \% \text { of usual dose in Liver } \\
\text { dysfunction }\end{array}$ \\
\hline \multirow[t]{2}{*}{ Morphine } & \multirow[t]{2}{*}{$\begin{array}{l}\text { Morphine-6-glucuronide may } \\
\text { accumulate causing increase sedation }\end{array}$} & $\begin{array}{l}\text { Adjust dose appropriate in patients } \\
\text { with renal dysfunction }\end{array}$ \\
\hline & & $\begin{array}{l}\text { Decrease frequency and dosage with } \\
\text { liver dysfunction }\end{array}$ \\
\hline Meperidine & $\begin{array}{l}\text { Accumulation of Normeperidine causing } \\
\text { CNS toxicity }\end{array}$ & $\begin{array}{l}\text { Not recommended in Renal and } \\
\text { Liver insufficiency }\end{array}$ \\
\hline \multirow[t]{2}{*}{ Oxycodone } & \multirow[t]{2}{*}{$\begin{array}{l}\text { Accumulation of parent and active } \\
\text { metobilite oxymorphone }\end{array}$} & $\begin{array}{l}\text { Use with caution with Renal } \\
\text { insufficiency }\end{array}$ \\
\hline & & $\begin{array}{l}\text { Reduce dose by } 1 / 3 \text { or } 1 / 2 \text { with } \\
\text { severe liver dysfunction } \\
\text { and cirrhosis }\end{array}$ \\
\hline
\end{tabular}

Table 2. Clinical Coping with Prescribing Opioid Analgesics and Disease States

Drug therapy is a vast territory and the prescribing provider cannot be expected to be familiar with more than a small fraction of it, but it is necessary and possible for them to know a small part of it that they need to do their daily work (200-300 agents), replacing the older ones with newer ones [6]. Furthermore, Dukes and Swartz (1998) assert that indeed it is feasible for a prescriber to learn and remember sufficiently about the drugs, which they use, to use them properly. Moreover, Dukes and Swartz (1998) report that there is no doubt that some physicians make little effort to acquit themselves of the duty to keep abreast of events of adverse effects. Dukes and Swartz (1998) state that major drug contraindications described in the literature have been overlooked by providers. They suggest that prescribing providers should have readily available resources of knowledge of all the significant risks associated with the drugs they use from day to day, including adverse drug interactions, drug-drug interactions or other frequent and severe contraindications [6]. Therefore, exercising an ignorance defense as it applies to opioid pharmacology, pharmacodynamics, pharmacokinetics, and even pharmacogenomics may not be a successful risk management strategy if an opioid medication error occurs to shield the opioid prescriber from a malpractice lawsuit. 
Kay (2020) declares that now providers bear much of the burden and blame for the US opioid addiction. Thus targeting prescribers is much easier than facing hard truths about poverty, disparities, and social inequity [10]. The advance nurse practitioner opioid prescriber must appreciate that management of chronic pain is complex and requires multi-disciplinary approaches. Opioids are just one tool in a provider's armamentarium for helping patients [10]. Finally, the prescribing of opioid analgesics as a highly individualized, patient-centered approach may be more beneficial than broad, all-encompassing policies [10].

\section{Conclusion}

The advance nurse practitioner should commit to the riskmitigating strategy that the best ways to prevent opioid overdose are the following: improve opioid prescribing practices, reduce exposure to opioids, prevent misuse, and treat opioid use disorder. Given, that medication errors to include an adverse event is beginning monitored by local, state, and federal agencies; then an inference that prescribing a medication to include opioids in of itself can be considered a risk to the advance nurse practitioner and their respective practice. The main purpose and goal for this review is to present data congruent with clinical, medical, and legal reports for appreciating the possibility for risk assumed when ordering and prescribing opioids. The concept and process for risk management viewing it in the context of rootcause analysis was and applying this prosses for identify risk when executing an opioid prescription has been presented. Secondly, using several examples found in both the medical and legal literature documenting details for opioid prescription risk was presented. Finally, mitigating strategies available from governmental and clinical base evidence for safe prescribing of opioids was presented so the advance nurse practitioner can be empowered to prevent opioid harm and to foster a safe environment for their patients they treat with opioid agents.

\section{References}

1. Bachtell J. (2019, August 1) Big pharma companies are the "drug kingpins" of the opioid crisis.

2. Berman, J. B., \& Li, G. (2020). Characteristics of criminal cases against physicians charged with opioid-related offenses reported in the US news media, 1995-2019. Injury epidemiology, 7(1), 50 .

3. CDC Understanding the epidemic: drug overdose (2016a). Accessed July 3, 2021

4. CDC (2016b) Assessing Benefits and Harms of Opioid Therapy (cdc.gov) (2016). Accessed July 7, 2021.

5. Dowell, D., Haegerich T.M., Chou, R (2016). MMWR CDC Guideline for Prescribing Opioids for Chronic Pain. rr6501e1.pdf (cdc.gov) pdf. Accessed .July 7, 2021.

6. Dukes, M G, Swartz, B. (1988). Responsibility for druginduced injury: A reference book for lawyers, the health professions and manufacturers / N. M. Graham Dukes and Barbara Swartz. Amsterdam : Elsevier.

7. https://academic.oup.com/painmedicine/articleabstract/21/1/76/5368063

8. Hazi A. (2019, August,1).The Risk of medical Malpractice Lawsuits for opioid-prescribing physician. Featured Insights Medical Malpractice Defence.
9. Burns White. (2021). The Risk of Medical Malpractice Lawsuits for Opioid-Prescribing Physicians - Accessed July 7, 2021.

10. https://link.springer.com/article/10.1007/s11606-019-05604-4

11. Kim, D. D., \& Sibai, N. (2020). The Current State of Opioid Prescribing and Drug Enforcement Agency (DEA) Action Against Physicians: An Analysis of DEA Database 20042017. Pain physician, 23(3), E297-E304.

12. Lowes R. (2017, July 7). Opioids Top List of Malpractice Claims Linked to Medications - Medscape.

13. Mann B. (2020, July 19) Doctors and Dentists Still Flooding U.S. With Opioid Prescriptions (2020). Accessed July 3, 2021.

14. McLaughlin, S.H (2018). Legally Prescribed Painkillers are Very Often a Precursor to Addiction, Overdose, and Drug Abuse. Opioid Malpractice Claims | McLaughlin \& Lauricella Attorneys (ml-law.net) accessed July 7, 2021.

15. National Quality Forum, (2018). National Quality Partners Playbook $^{\mathrm{TM}}$. Opioid Stewardship. Washington, DC: NQF. Accessed July 7, 2021.

16. Nelson KL (2018, August 19). Purdue Pharma targeted nurse practitioners, PAs to prescribe OxyContin (knoxnews.com) Accessed July 7, 2021.

17. Netherland, J., \& Hansen, H. (2017). White opioids: Pharmaceutical race and the war on drugs that wasn't. BioSocieties, 12(2), 217-238.

18. Perrone, J., Weiner, S. G., \& Nelson, L. S. (2019). Stewarding Recovery from the Opioid Crisis Through Health System Initiatives. The western journal of emergency medicine, 20(2), 198-202.

19. Pollock, M., Bazaldua, O. V., \& Dobbie, A. E. (2007). Appropriate prescribing of medications: an eight-step approach. American family physician, 75(2), 231-236.

20. https://www.ncbi.nlm.nih.gov/pmc/articles/PMC6384031/

21. Smith R. G. (2006). A review of opioid analgesics frequently prescribed by podiatric physicians. Journal of the American Podiatric Medical Association, 96(4), 367-373.

22. Smith R.G. (2018). Using Clinical-Based Evidence as the Sextant to Prescribe and Navigate through the Opioid CrisisOpioid Crisis Management. Foot and Ankle Quarterly, fall 29(3), 143-157.

23. Smith R. G. (2020a). The Opioid Crisis Viewed Through the Lens of a Black and White Camera. J Clin Rev Case Rep, 5(9), 404-415.

24. Smith R. G. (2020b). Mitigating the Opioid Crisis for Wound Care Providers Using Opioid Stewardship. Wounds : a compendium of clinical research and practice, 32(6), 146-151.

25. Smith R. G. (2020c). Mitigating the Opioid Crisis for the Podiatric Physician: Remembering the Morphine acronym. R.G. Smith Podiatry Management, 39(3), 105-107.

26. Smith R. G. (2020d). Mitigating the opioid crisis for the lower extremity provider opioid stewardship programs. Foot (Edinburgh, Scotland), 45, 101708.

27. Van Zee A. (2009). The promotion and marketing of oxycontin: commercial triumph, public health tragedy. American journal of public health, 99(2), 221-227.

28. Varley, P. R., \& Zuckerbraun, B. S. (2018). Opioid Stewardship and the Surgeon. JAMA surgery, 153(2), e174875.

29. Yorkgitis, B. K., \& Brat, G. A. (2018). Postoperative opioid prescribing: Getting it RIGHTT. American journal of surgery, 215(4), 707-711. 